\title{
British English norms for the spontaneous completion of three-letter word stems
}

\author{
Ellen M. Migo, Adrian Roper, Daniela Montaldi, And Andrew R. Mayes \\ University of Manchester, Manchester, England
}

\begin{abstract}
Word stem completion tasks involve showing participants a number of words and then later asking them to complete word stems to make a full word. If the stem is completed with one of the studied words, it indicates memory. It is a test widely used to assess both implicit and explicit forms of memory. An important aspect of stimulus selection is that target words should not frequently be generated spontaneously from the word stem, to ensure that production of the word really represents memory. In this article, we present a database of spontaneous stem completion rates for 395 stems from a group of 80 British undergraduate psychology students. It includes information on other characteristics of the words (word frequency, concreteness, imageability, age of acquisition, common part of speech, and number of letters) and, as such, can be used to select suitable words to include in a stem completion task. Supplemental materials for this article may be downloaded from http://brm .psychonomic-journals.org/content/supplemental.
\end{abstract}

Word stem completion (WSC) tasks have a long history of use in psychology, where their initial introduction indicated that implicit memory can be preserved in amnesic patients (Warrington \& Weiskrantz, 1970). Participants are shown lists of words, unaware of a later memory task. Subsequently, they are presented with the first few letters of a word and are asked to complete this stem with the first word that comes to mind (see Roediger, Weldon, Stadler, $\&$ Riegler, 1992, for a review). Explicit memory versions ask for completions that are remembered from the study list (Greene, 1986). An increase in stem completion levels due to preexposure of the words indicates memory. This methodology is still widely used in tasks ranging from cerebral blood flow measures (Sorond, Schnyer, Serrador, Milberg, \& Lipsitz, 2008) to behavioral tasks in healthy participants (Benjamin Clarke \& Butler, 2008) and patients (e.g., Alzheimer's disease, LaVoie \& Faulkner, 2008; schizophrenia, Pope \& Kern, 2006).

The selection of words to use in WSC tasks is critical. The stem must be able to form multiple words when completed. Words should not be proper nouns and should have sufficient frequency for participants to know them and their meanings. They should have relatively matched imageability and concreteness. Information on these characteristics is available through established databases (e.g., M. Wilson, 1988).

One key criterion, particularly important for implicit tasks, is that the words used should not commonly be produced in a spontaneous WSC task. Since participants must generate the first completion that comes to mind, a frequent spontaneous completion reduces the distance between chance and ceiling performance. In imaging studies, "correct" responses would be more likely to be guesses, adding unwanted noise to the neural signal. Matching low levels of spontaneous WSC across word lists - and ideally, all words - ensures that tasks are sensitive and reliable.

Spontaneous WSC rates are not easily available, and studies have run pilot tests (e.g., Fleischman et al., 2002; D. E. Wilson \& Horton, 2002) or approximated rates from whole-word frequency (e.g., Chiarello \& Hoyer, 1988; Pope \& Kern, 2006). The available databases are based on different languages (Martin et al., 2009; Olofsson \& Nyberg, 1992) and, thus, are of limited value to Englishspeaking populations, or they use few stems (Graf \& Williams, 1987; Lee \& Leslie, 2003). Data have been collected for 914 stems using American undergraduate students (Shaw, 1997), but completions include multiple (e.g., air bag), hyphenated (e.g., cul-de-sac), and abbreviated (e.g., aren't) words. In addition, raw numbers of completions, rather than more interpretable proportions, have been reported, without any additional information on other characteristics of the words. To the best of our knowledge, there is no large source of rates of spontaneous WSC, particularly using British English; this article presents such a database.

We generated a list of 395 potential three-letter word stems from which each of 80 participants viewed a selection of 200 stems. The participants were asked to complete them with the first word that came to mind. Results are presented as a WSC frequency database including data for each word on frequency, concreteness, imageability, age of acquisition, common part of speech, and number of letters.

E.M. Migo, ellen.migo@kcl.ac.uk 


\section{METHOD}

\section{Participants}

The participants ( $N=80 ; 6$ of them male; average age, 20 years) were recruited from undergraduate students in the School of Psychological Sciences at the University of Manchester and received course credit for participating. Ethical approval was received from the School of Psychological Sciences Research Ethics Committee.

\section{Materials}

A list of 395 three-letter word stems was generated (see the Appendix), using materials from other WSC tasks and identifying stems from the dictionary where multiple words $(\geq 4)$ could be completed.

\section{Procedure}

Stems were presented individually on a computer screen using E-Prime (Psychology Software Tools, Pittsburgh, PA), and the participants were asked to finish each one with the first word that came to mind, avoiding proper nouns. If they could not find a completion within $10 \mathrm{sec}$, they were asked to enter a question mark. This timed cutoff for responding is in keeping with behavioral tasks (e.g., Fleischman, Wilson, Gabrieli, Bienias, \& Bennett, 2004; Roediger et al., 1992). Responses were made by typing the remainder of the word, which appeared on the screen. Each participant viewed a randomly ordered, random selection of 200 stems from the full list of 395 to avoid participant fatigue and maintain motivation. The experiment was self-paced, taking between 8 and $20 \mathrm{~min}$.

\section{RESULTS}

\section{Data Cleaning}

Data were checked for British spelling, and proper nouns, such as Manchester, were excluded. To avoid substantial data loss, exceptions to this were months of the year and days of the week (e.g., for the fri stem, Friday was produced $71 \%$ of the time) and nationalities (e.g., German for ger), which can be used as adjectives and have a common noun meaning. Individual, well-established proprietary names were not excluded-for example, sellotape, google, and hoover - since these have entered general usage and are not generally viewed as brand distinctive (e.g., google, meaning to search). Words were excluded when a spelling correction changed the three-letter stem (e.g., aqua incorrectly spelled as acqua was deleted, whereas necter as a misspelling of nectar was corrected and included).

Incorrectly spelled words that could not be identified were excluded, as were two-word answers (e.g., cat woman). The average number of included words for each participant was 191.5, and each stem was presented to and received a valid response from an average of 38.8 participants (range, 24-61). The mean proportion of a "?" response - that is, when the participants could not think of a word to complete within $10 \mathrm{sec}$ - was $9.57 \%$.

Different derivations of the same word were not amalgamated (e.g., abbot and abbots were left separate), but it may be appropriate to do this in many circumstances.

\section{Results Output}

The results are presented as an online database (see supplemental information for raw data): http://personalpages .manchester.ac.uk/staff/Andrew.Mayes/wordcount/.
Using the database, a stem can be selected to view the frequency of the spontaneously completed words. This includes the frequency with which the participants could not produce a word to complete any given stem (shown by a question mark). The database also displays various other characteristics of words (word frequency, concreteness, imageability, age of acquisition, common part of speech, and number of letters), where these norms were available.

We have also generated an example list of 200 words that could be used in memory tasks, with a spontaneous stem completion rate cutoff of less than $5 \%$, for which imageability and concreteness ratings were available (taken from M. Wilson, 1988). This includes words that were never produced as completions but match all the other criteria (see the supplemental information for full details). Since the ratings are available only for a subset of words, it may not always be possible to use them as criteria. However, there will be many other equally suitable approaches to word selection, such as avoiding all stems that are words in themselves (e.g., cat/tab) or taking words from the same part of speech (e.g., nouns). The supplemental information allows calculation of WSC rates for specific parts of speech, if needed.

\section{DISCUSSION}

We have provided a database of spontaneous WSC rates for 395 stems. At least 24 people gave a valid completion (or indicated they could not think of one) to each stem. These data can be used to ensure that targets in both explicit and implicit memory WSC tasks are not likely to be guessed by participants. Such careful stimulus selection should ensure that memory will be indexed as reliably as possible.

This approach is more likely to be useful than basing selection on whole-word frequency. For example, using the word stem aut, the most frequently completed word was autumn (51.52\%), with authority having a much lower rate $(3.03 \%)$. Comparing these WSC rates against word frequency (Kučera \& Francis, 1967, taken from M. Wilson, 1988; Leech, Rayson, \& Wilson, 2001), the more frequent completion (autumn) has a lower frequency (22 vs. 93 with Kučera \& Francis, 1967; 39 vs. 183 with Leech et al., 2001). Using word frequency as an estimate of spontaneous WSC rates may, therefore, be misleading, since it is a variable and, at best, moderate predictor of completion (Graf \& Williams, 1987; Shaw, 1997). Our example list of words for memory studies uses a very low cutoff of spontaneous WSC (below 5\%). This is an arbitrary level, and the most appropriate level of spontaneous completion rates for optimal priming/cued-recall performance has not been demonstrated. Using words that are never completions in a spontaneous task may in itself bias performance, but having a database providing the information can inform word selection, regardless of criterion chosen.

The database presented is based on a sample of U.K. undergraduate psychology students. Although these responses may not extrapolate to other populations, the data can help 
indicate words that are more appropriate than others. The importance of culturally appropriate norms is highlighted by a comparison against an American college population (Shaw, 1997). Their data would have excluded $23 \%$ of the words in our example list, since the stem completion rates from their sample were above $5 \%$. However, against other published rates from North American samples, we can show a good match. Comparing rates for lists published in Brooks, Gibson, Friedman, and Yesavage (1999), our database produces mean rates for each list (where stems overlap) that are different only by an average of $1.9 \%$. This suggests at least some utility for non-British samples.

In combination with other established databases on word characteristics (e.g., Leech et al., 2001; StadthagenGonzalez \& Davis, 2006; M. Wilson, 1988), our data provide additional information for stimulus selection. This should be helpful to those conducting WSC memory studies, due to the large number of stems and the participants sampled, who represent the population used in many experiments run in universities. The database allows researchers to control for spontaneous completion rates, an often overlooked, but critically important, aspect of word selection.

\section{AUTHOR NOTE}

We thank Yu Li for his work in creating the database, as well as Taha Gholipour and Lea Soei for their contribution to the selection of word stems, Kishaani Suseeharan for helping to check data entry, and Owen O'Daly for programming help. We are grateful to Gregory Francis, Colin MacLeod, and two anonymous reviewers for their feedback on a previous draft of the manuscript. Correspondence concerning this article should be addressed to E. M. Migo, Centre for Neuroimaging Sciences, PO89, Institute of Psychiatry, De Crespigny Park, London SES 8AF, England (e-mail: ellen.migo@kcl.ac.uk).

\section{REFERENCES}

Benjamin Clarke, A. J., \& Butler, L. T. (2008). Dissociating word stem completion and cued recall as a function of divided attention at retrieval. Memory, 16, 763-772.

Brooks J. O., III, Gibson, J. M., Friedman, L., \& Yesavage, J. A. (1999). How to drastically reduce priming in word stem completionand still present the words. Memory \& Cognition, 27, 208-219.

Chiarello, C., \& Hoyer, W. J. (1988). Adult age differences in implicit and explicit memory: Time course and encoding effects. Psychology \& Aging, 3, 358-366. doi:10.1037/0882-7974.3.4.358

Fleischman, D. A., Monti, L. A., Dwornik, L. M., Moro, T. T., BenNETT, D. A., \& GABRIELI, J. D. E. (2002). Impaired production priming and intact identification priming in Alzheimer's disease. Journal of the International Neuropsychological Society, 7, 785-794.

Fleischman, D. A., Wilson, R. S., Gabrieli, J. D. E., Bienias, J. L., \& BENNETT, D. A. (2004). A longitudinal study of implicit and explicit memory in old persons. Psychology \& Aging, 19, 617-625. doi:10.1037/ 0882-7974.19.4.617

GraF, P., \& Williams, D. (1987). Completion norms for 40 three-letter word stems. Behavior Research Methods, Instruments, \& Computers, 19, 422-445.

GreENe, R. L. (1986). Word stems as cues in recall and completion tasks. Quarterly Journal of Experimental Psychology, 38A, 663-673.

KUČERA, H., \& FrANCIS, W. N. (1967). Computational analysis of presentday American English. Providence, RI: Brown University Press.

LaVoie, D. J., \& FaulKner, K. M. (2008). Production and identification repetition priming in amnestic mild cognitive impairment Aging, Neuropsychology, \& Cognition, 15, 523-544. doi:10.1080/ 13825580802051497

LeE, L., \& LESLIE, K. (2003). Target words for the Word Stem Completion test in Australian patients. Anaesthesia \& Intensive Care, 31, 184-186.

LEECH, G., RAYSON, P., \& WILSON, A. (2001). Word frequencies in written and spoken English. Harlow, U.K.: Longman.

Martin, S., Dressaire, D., Guerdoux, E., Trouillet, R., Brouillet, D., Brouillet, T., \& Maury, P. (2009). French word-stem completion norms by participants from 30 to 93 years old. Revue Européenne de Psychologie Appliquée, 59, 25-36. doi:10.1016/j.erap 2008.09.001

OlofsSon, U., \& Nyberg, L. (1992). Swedish norms for completion of word stems and unique word fragments. Scandinavian Journal of Psychology, 33, 108-116. doi:10.1111/j.1467-9450.1992.tb00890.x

Pope, J. W., \& Kern, R. S. (2006). An "errorful" learning deficit in schizophrenia? Journal of Clinical \& Experimental Neuropsychology, 28, 101-110. doi:10.1080/13803390490918138

Roediger, H. L., III, Weldon, M. S., Stadler, M. L., \& Riegler, G. L. (1992). Direct comparison of two implicit memory tests: Word fragment and word stem completion. Journal of Experimental Psychology: Learning, Memory, \& Cognition, 18, 1251-1269. doi:10.1037/0278 $-7393.18 .6 .1251$

SHAW, R. J. (1997). Unprimed stem completion is only moderately predicted by word frequency and length. Behavior Research Methods, Instruments, \& Computers, 29, 401-424.

Sorond, F. A., Schnyer, D. M., Serrador, J. M., Milberg, W. P., \& Lipsitz, L. A. (2008). Cerebral blood flow regulation during cognitive tasks: Effects of healthy aging. Cortex, 44, 179-184. doi:10.1016/ j.cortex.2006.01.003

Stadthagen-Gonzalez, H., \& Davis, C. J. (2006). The Bristol norms for age of acquisition, imageability, and familiarity. Behavior Research Methods, 38, 598-605.

WARRINGTON, E. K., \& WeisKrantZ, L. (1970). Amnesic syndrome: Consolidation or retrieval? Nature, 228, 628-630. doi:10.1038/228628a0

WiLson, D. E., \& HorTON, K. D. (2002). Comparing techniques for estimating automatic retrieval: Effects of retention interval. Psychonomic Bulletin \& Review, 9, 566-574.

WILSON, M. (1988). MRC Psycholinguistic Database: Machine-usable dictionary, version 2.00. Behavior Research Methods, Instruments, \& Computers, 20, 6-10.

\section{SUPPLEMENTAL MATERIALS}

The raw data discussed in this article, as well as norms for 200 words that may be used in stem completion studies, may be downloaded from http://brm.psychonomic-journals.org/content/supplemental. 
APPENDIX

List of All Word Stems Used

\begin{tabular}{|c|c|c|c|c|c|c|c|c|c|c|c|}
\hline aba & ana & bio & cli & emp & gle & inv & men & pea & rav & sol & tra \\
\hline $\mathrm{abb}$ & anc & bir & clo & enc & glo & jac & mer & pen & rea & sou & tre \\
\hline $\mathrm{abd}$ & ang & bis & $\operatorname{coc}$ & end & gol & jer & met & per & $\mathrm{rec}$ & spa & tri \\
\hline abi & ani & bla & com & ent & goo & jou & mil & pet & ref & spe & tro \\
\hline $\mathrm{abl}$ & ann & blo & cor & epi & gor & jun & $\min$ & pha & reg & spi & tru \\
\hline abo & ant & blu & cou & esc & gra & kil & mis & pho & rel & squ & tur \\
\hline abr & apo & boo & cra & est & gre & kin & $\bmod$ & pic & rep & sta & twi \\
\hline abs & app & bou & cre & $\exp$ & gri & kit & mon & pil & res & ste & ult \\
\hline aca & ara & bra & cri & fac & gro & kna & mor & pit & rin & sti & uni \\
\hline acc & arb & bre & cur & fal & gua & kni & $\operatorname{mos}$ & pla & ris & sto & vac \\
\hline ach & arc & bri & dan & fam & gui & kno & mot & ple & roa & str & val \\
\hline $\mathrm{acq}$ & arm & bro & deb & fan & hab & lan & mou & plo & roo & stu & van \\
\hline $\mathrm{acr}$ & $\operatorname{arr}$ & bur & def & fat & hal & lar & mus & plu & rou & suc & var \\
\hline act & art & but & del & fea & han & lat & mut & pol & rus & sul & ven \\
\hline add & asp & cab & dem & fel & har & lea & nat & pom & sab & sum & ver \\
\hline adj & ass & cal & dep & fer & hea & leg & nec & pop & sac & sup & vic \\
\hline $\mathrm{adm}$ & ast & cam & des & fil & her & lib & neg & por & sag & sur & vil \\
\hline ado & att & can & det & fin & hil & lig & neu & pos & sal & swe & vis \\
\hline $\mathrm{adv}$ & aut & cap & dia & fla & hin & $\lim$ & nig & pou & sat & swi & vit \\
\hline aer & awa & car & dis & fle & hol & $\operatorname{lin}$ & not & pra & sca & tab & vol \\
\hline aff & bac & cas & doc & for & hom & loc & obs & pre & sco & tac & wag \\
\hline afr & bal & cat & dra & fra & hoo & 100 & occ & pri & scr & tal & wal \\
\hline aft & ban & cel & dre & fre & hor & lum & oct & pro & $\mathrm{scu}$ & $\tan$ & war \\
\hline ali & bar & cen & dri & fri & hou & mac & off & psy & sec & $\operatorname{tar}$ & wea \\
\hline all & bas & cer & dro & fro & hum & mag & ope & pul & sel & tee & whi \\
\hline alm & bat & cha & duc & gal & hun & $\mathrm{mal}$ & ora & pun & sen & tel & wil \\
\hline alo & bea & che & dun & gam & hyd & man & org & pur & ser & ten & win \\
\hline alt & bee & chi & dyn & gan & ill & mar & pal & qua & sha & ter & woo \\
\hline ama & beg & cho & ear & gar & $\mathrm{imp}$ & mat & pan & qui & she & thi & wor \\
\hline $\mathrm{amb}$ & beh & chu & eff & gau & inc & mea & pap & $\mathrm{rac}$ & shi & thr & wre \\
\hline ami & bel & cir & ele & gen & ind & med & par & $\mathrm{rad}$ & sho & thu & wri \\
\hline amo & ben & cla & eli & ger & ins & mel & pas & rai & $\sin$ & tom & yea \\
\hline amp & ber & cle & $\mathrm{emb}$ & gla & int & mem & pat & ran & sla & tor & \\
\hline
\end{tabular}

(Manuscript received April 27, 2009;

revision accepted for publication October 24, 2009.) 